\title{
UTILIZAÇÃO DA LÓGICA PARACONSISTENTE EM PROCESSOS DE TOMADA DE DECISÃO: UM CASO PRÁTICO
}

\author{
APPLICATION OF PARACONSISTENT LOGIC IN DECISION TAKING \\ PROCESSES: A PRACTICAL CASE
}

\begin{abstract}
Cida Sanches
Faculdade Campo Limpo Paulista - SP
\end{abstract}

\section{Manuel Meireles}

Faculdade Campo Limpo Paulista - SP

\section{Marcio Luiz Marietto}

Universidade Positivo - PR

\section{Orlando Roque da Silva}

Faculdade Campo Limpo Paulista - SP

\section{José Osvaldo De Sordi}

Faculdade Campo Limpo Paulista - SP

\section{RESUMO}

A pesquisa abordou o processo de tomada de decisão de gestores utilizando-se de algoritmo paraanalisador baseado em lógicas não-clássicas: a lógica paraconsistente anotada (LPA). 0 método é apropriado ao tratamento de dados incertos, contraditórios ou paracompletos; consiste em estabelecer proposições e parametrizá-las para isolar os fatores de maior influência nas decisões. Especialistas são utilizados para obtenção de anotações sobre esses fatores, atribuindo-lhes graus de crença e descrença. No caso analisado, utilizou-se da LPA como instrumento de apoio ao processo de avaliação e seleção de profissional a ser promovido a gerente, dentre cinco possíveis, em pequena empresa familiar. Os três sócios-gerentes da empresa constituíram o grupo de especialistas, na medida em que conhecem o valor profissional dos cinco funcionários. A interpretação das avaliações realizadas pelos especialistas deu-se por intermédio dos baricentros no quadrado unitário do plano cartesiano (QUPC), que indicou os graus de inconsistência ou de indeterminação dos dados utilizados.

Palavras-chave: Lógica paraconsistente. Tomada de decisão. Processos de avaliação. Seleção.

\begin{abstract}
The research approached the process of decision making of managers using para-analyzer logarithm based on not-classic logics: the paraconsistent logic noted (LPA). The method is appropriate to the uncertain, contradictory or paracomplete data handling; it consists in establishing proposals and create parameters to isolate the factors of bigger influence in the decisions. In the analyzed case the LPA was used as instrument of support to the evaluation process and election of a professional to be promoted to manager. The three partnercontrolling of the company had constituted the group of specialists, in the measure where they know the professional value of each one of the employees. The interpretation of the evaluations carried by the specialists was given for intermediary of the barycentres in the unitary square of cartesian plan (QUPC) that indicated the degrees of contradiction and inconsistency or indetermination of the used data. The results were coherent with the expectations.
\end{abstract}

Keywords: Paraconsistent logic. Decision making. Evaluation process. Selection 


\section{INTRODUÇÃO}

A utilização da lógica paraconsistente anotada (LPA) em processos de tomada de decisão constituiu o objetivo da pesquisa descrita neste artigo. O objetivo do trabalho vincula-se, portanto, à tomada de decisão e faz uso de um caso para ilustrar a técnica. Foi feita a aplicação da técnica LPA em uma empresa familiar, de pequeno porte, com vistas a colaborar no processo de seleção de um profissional, dentre vários, ao cargo de gerente.

A lógica Paraconsistente vem ganhando espaço no campo da Administração. São exemplos disso os trabalhos de Oliveira e Abe (2002) que mostraram o uso desta técnica para validar processos de negócios; de Hasegawa (2004) que usa a mesma técnica para avaliação de ofertas em negociações entre organizações artificiais; de Carvalho et al. (2003) que fizeram a avaliação do projeto de uma fábrica; de de Ito et al. (2009) que investigaram a aplicação da lógica paraconsistente anotada no estudo de questionário com informações redundantes. Já são muitos os exemplos e aplicações da lógica Paraconsistente na Administração, embora sua utilização esteja concentrada na área de gestão da produção e de sistemas de informação, decorrente da proximidade deste grupo com pesquisadores da área de engenharia de software, área com amplo domínio e prática da abordagem da lógica Paraconsistente. Com o objetivo de evitar uma percepção de "abordagem de nicho", julga-se pertinente complementar o objetivo específico, ficando assim definido: descrever as características centrais da técnica da lógica Paraconsistente com a apresentação de exemplo conduzido no campo da gestão de recursos humanos.

A empresa na qual ocorreu o experimento é familiar e possui uma estrutura profissionalizada, sendo dirigida por três irmãos. Os demais colaboradores são todos profissionais contratados. Os irmãos, atuais gerentes, apresentam espírito empreendedor, capacidade intelectual e disposição para a busca do crescimento e do desenvolvimento da empresa e são atuantes nas decisões da organização, inovando, implantando e revendo processos. A busca pela inovação é constante e é esta busca que possibilitou a realização da aplicação da LPA face à necessidade de promover a gerente um dos diversos chefes de setores. Quanto ao método empregado, aplicaram-se as técnicas de maximização (OR) e de minimização (AND) da LPA, para chegar a um resultado final, que, analisado perante o quadrado unitário do plano cartesiano real (QUPC), com um determinado grau de exigência, constituiu um valioso subsídio para a decisão final (CARVALHO, 2002).

\section{REFERENCIAL TEÓRICO}

O núcleo principal da presente pesquisa refere-se a um processo de tomada de decisão. A primeira preocupação ao focalizar o processo decisório é conceituá-lo e caracterizá-lo no contexto organizacional, pois, segundo Freitas et al. (1997, p.52), é por meio de suas decisões que os administradores procuram conduzir a empresa a uma situação desejada. Por isso, diz Pereira (1997), devido às grandes transformações que estão ocorrendo no mundo atual, às decisões tomadas traz conseqüências diretas e imediatas para a empresa. Segundo Simon (1965, p.54), as decisões são algo mais que simples proposições factuais: "Para ser mais preciso, elas são descrições de um futuro estado de coisas, podendo essa descrição ser verdadeira ou falsa, num sentido empírico. Por outro lado, elas possuem, também, uma qualidade imperativa, pois selecionam um estado de coisas futuro em detrimento de outro e orientam o comportamento rumo à alternativa escolhida".

Jones (1973, p.28) considera a decisão como um curso de ação escolhido por aquele que decide, que optou por determinado caminho por julgá-lo o mais eficiente à sua disposição para alcançar os objetivos ou o objetivo visado no momento -- ou seja, a melhor maneira de resolver um problema em aberto. Diz ainda que uma decisão é algo bem diferente do desempenho real, do ato que a inspirou: é uma conclusão a que chegou um homem a respeito do que ele deve fazer em seguida. Também enfatiza que a decisão é uma solução selecionada depois do exame de várias alternativas -- escolhida, porque, aquele que decide, imagina ser o caminho selecionado o mais eficaz para cumprir as metas programadas. 
Pode-se dizer assim, argumentam Chagas e Freitas (2001), que uma decisão baseia-se em conhecimentos ou crenças sobre as relações de causa e efeito das opções disponíveis, e visa à alternativa, cujas conseqüências são preferíveis. Quando o administrador não tem o domínio das variáveis, às vezes fundamentais para o bom desempenho de seu trabalho, há o risco de gerenciar um processo decisório mal sucedido (TEIXEIRA E PELLEGATI, 1986). Segundo Freitas et all (1997, p.52), as variáveis mais importantes, que interferem no processo de tomada de decisões, são: os objetivos da organização, os critérios de racionalidade e de eficácia, as informações (a falta ou excesso, situação de incerteza, complexidade e conteúdo), o raciocínio, os valores, as crenças, os recursos, etc. Estas variáveis servem de apoio ao decisor, principalmente quando o conteúdo das informações possibilita formar uma base de conhecimento e ajuda no raciocínio, contribuindo para a formação de valores positivos (recursos) e a eliminação de crenças ou mitos, encaminhando o administrador para decisões acertadas e sua execução (ações).

No caso analisado, a tomada de decisão tinha por objetivo eleger, dentre diversos funcionários, um à categoria de gerente. Imprescindível, portanto, que os potenciais gerentes tivessem capacidade para 0 exercício de tal papel. Mintzberg (1977, p.27) trabalha com três categorias básicas de papéis gerenciais, e os classifica em: papéis interpessoais; papéis informacionais; e papéis decisórios. Os papéis interpessoais decorrem do status e autoridade inerente aos cargos administrativos, são, em grande parte, de natureza social e legal, implicando no relacionamento do gerente com representantes da organização, com os subordinados e com indivíduos ou grupos externos à organização. Os papéis informacionais estão diretamente ligados às informações recebidas pelos gerentes, com a finalidade de se inteirar do que acontece na organização, e posteriormente transmitidas aos subordinados ou quando se torna o porta-voz da unidade/organização, falando em seu nome. Os papéis decisórios relacionam-se às tarefas de tomar decisões, seja através das atividades de planejamento, solucionador de problemas, alocador de recursos, negociador, dentre outras.

Tais papéis gerenciais requerem habilidades específicas. Katz (1986, p.60) afirma que ter habilidade implica ter uma capacidade que pode ser desenvolvida, e não necessariamente inata, que se manifesta no desempenho e não apenas em potencial. A habilidade deve ser voltada para a prática de uma ação eficiente, seja em que circunstância for. As habilidades de um administrador eficiente, segundo este autor, estão inseridas em três contextos: técnica, humana e conceitual. A habilitação técnica relacionase com o manuseio das coisas, como processos ou objetos físicos; a habilitação humana é a habilidade de trabalhar com outras pessoas e de conhecer a si próprio (atitudes, opiniões e conviç̧ões) e seu grupo de trabalho; a habilidade conceitual, considerada a habilidade criativa do administrador, é a faculdade de visualizar a empresa como um todo.

A empresa analisada buscava a promoção de um profissional recrutado internamente entre pessoas que possuíam, de alguma forma, um leque de capacidades já apontadas por Baush (1991, p.6): capacidade de identificar prioridades; capacidade de operacionalizar idéias; capacidade de delegar funções; habilidade para identificar oportunidades; capacidade de comunicação, redação e criatividade; capacidade de trabalho em equipe; capacidade de liderança; disposição para correr riscos e responsabilidade; facilidade de relacionamento interpessoal; domínio de métodos e técnicas de trabalho; capacidade de adaptar-se a normas e procedimentos; capacidade de estabelecer e consolidar relações; e capacidade de subordinar-se e obedecer à autoridade.

Embora se trate de uma decisão gerencial, não se pode esquecer do contexto onde ela é tomada: numa pequena empresa familiar. De acordo com Levin (1993) a organização familiar pode ser concebida em termos de uma "realidade mapeada" ou de uma "categoria realizada" (BOURDIEU, 1993). Estas concepções de organização familiar destacam a necessidade de levar em conta questões mais complexas oriundas da experiência cotidiana e das interpretações que os membros (e não membros) elaboram a respeito da família. Tais interpretações são socialmente construídas e ajudam a conferir sentido à realidade que eles descrevem. Uma concepção alternativa da organização familiar poderia ser baseada numa abordagem mais interpretativa, numa abordagem que permitisse um exame do conceito de família tal qual ele é interpretado e construído pelos indivíduos inseridos na organização (LEVIN, 1993). A cultura familiar poderia, então, ser apreciada e estudada por intermédio do discurso 
familiar - forma de relatar, de conferir significados e de criar sentido dos relacionamentos. Para alguns estudiosos, tais significados são permanentemente negociados dentro do contexto organizacional familiar (RAM, 1994; RAM E HOLLIDAY, 1993). Para estes últimos, o grau de complexidade e de contradição que a família imprime nas dinâmicas de trabalho é resultado de um processo predominantemente contingente e negociado, também em termos de etnia e gênero.

Fletcher (2000) afirma que em organizações familiares as relações sociais são mais coesas e intensas; envolvem relacionamentos familiares que possuem uma longa história, pois se desenvolvem também fora da organização, abrangendo a infância e a adolescência de seus membros. Nas organizações familiares, um longo período de convivência e um conhecimento de experiências partilhadas e de eventos passados convergem na influência de atividades, eventos e relacionamentos correntes (FLETCHER, 1998). Dessa forma, nas organizações familiares, as ligações pessoais, os laços emocionais e os vínculos de afeição (que caracterizam qualquer organização) são possivelmente mais complexos, enraizados e imbricados neste tipo de organização.

O uso da LPA, neste contexto, expressa as dinâmicas de trabalho levadas a cabo e o processo de inovação cuidadosamente considerado pelos atuais gerentes. A LPA está cada vez mais, incorporandose aos modelos de decisões e constitui uma nova categoria de lógica que surgiu como disciplina autônoma, na década de 1950. Ela difere significativamente da lógica formal que usualmente pode ser expressa por meio de enunciado condicional. Dentre os argumentos condicionais, a primeira forma de argumento válido é chamada afirmação do antecedente (às vezes modus ponens) cuja forma, segundo Salmon (1984, p.41) pode ser descrita pelo seguinte esquema:

Se p, então q.

p.<smiles>[TeH]</smiles>

Os enunciados condicionais são enunciados complexos com dois enunciados componentes que se ligam por meio da expressão "se... então..." (p.38). Num enunciado condicional, a parte ligada ao "se" denomina-se antecedente e a parte que se apresenta após o "então" se denomina conseqüente.

Copi (1981, p.235), afirma que os argumentos formulados em qualquer língua natural são, com freqüência, de avaliação difícil por causa da natureza vaga e equívoca das palavras, da ambigüidade ou duplicidade de sentido da sua construção, dos idiotismos da linguagem, do seu estilo metafórico, possivelmente confuso, e do elemento de distração derivado de qualquer significação emotiva que se lhes possam atribuir. Para evitar estas dificuldades ele entende ser conveniente "criar uma linguagem simbólica artificial, livre desses defeitos, na qual possam ser expressos os enunciados e raciocínios da linguagem natural".

A análise lógica procura examinar as relações que existem entre uma conclusão e a evidência (Premissas) que lhe serve de apoio. Um Argumento é uma coleção de enunciados que estão relacionados uns com os outros. Um Argumento consiste em um ou mais enunciados de evidência colaboradora, chamados Premissas, e num outro enunciado chamado Conclusão. As Premissas de um Argumento devem apresentar evidência, sempre que possível, que colaborem com a Conclusão. As Premissas podem, evidentemente, ser falsas ou verdadeiras, isto é, podem enunciar os fatos de modo, respectivamente, não legítimo ou legítimo. Além disso, as Premissas devem estar relacionadas de maneira adequada com a Conclusão.

A análise Lógica, que trata da relação entre as Premissas e a Conclusão, deixa de se importar com a verdade ou a falsidade das Premissas. Denomina-se Falácia, o Argumento logicamente incorreto. Como foi dito, a correção ou incorreção lógica de um Argumento é inteiramente independente da verdade ou falsidade das Premissas.

Uma análise lógica de uma decisão, de acordo com Cerqueira e Oliva (1979, p.18) abrange alguns 
passos, a saber :

I - Os Argumentos precisam ser reconhecidos como tais. Isto exige que o analista da lógica garimpe o histórico da decisão, procurando os Argumentos que a sustentaram: suas Premissas e Conclusões;

II - É preciso identificar claramente as Premissas e a Conclusão gerada por elas;

III - Se o Argumento for incompleto é preciso tentar explicar as Premissas omitidas.

A Lógica Formal assenta-se, desta forma, sobre dois núcleos polares: Verdade ou Falsidade. Já a Lógica Paraconsistente admite outros estados, derivados da premissa de que o conhecimento é incerto.

Para Oliveira e Abe (2002), a veracidade ou a falsidade das premissas é o principal problema que envolve a estrutura da lógica clássica, isso porque na aplicação da lógica no mundo real devem-se investigar fenômenos para fazer predição sobre comportamentos. Essas investigações dos fenômenos são, a cada dia, mais aprofundadas e mais precisas, gerando contradições. Com o avanço tecnológico, é impossível a resolução de problemas de inconsistências, simplesmente, ignorando-as, refutando-as como falsas ou confirmando-as como verdadeiras. Podem existir casos em que as proposições podem ser verdadeiras e as inferências são ilegítimas, portanto, argumentos válidos podem ser conclusões verdadeiras ou falsas. A validez de um argumento não garante a verdade da conclusão.

As Lógicas Paraconsistentes (anotadas, modais ou indutivas) fazem parte de um conjunto de lógicas heterodoxas que compreendem também lógicas: paracompletas, não aléticas, quânticas, relevantes, epistêmicas paracompletas e indutivas paraconsistentes. A lógica paraconsistente anotada é uma classe de lógicas, lógicas estas que se podem expressar por certos reticulados como mostra a figura 1. 0 primeiro estudo sistemático da lógica anotada foi desenvolvido por Da Costa, Subrahmanian e Vago, em 1991, partindo de um trabalho de 1987 de Subrahmanian sobre o mesmo tema.

Tal lógica parte do princípio que é possível estabelecer, numa escala de 0 a 1 , graus de crença e de descrença para certas proposições. Seja a proposição p = "Pedrinho está acometido de tumor maligno", se se anotar com $(1 ; 0)$ a leitura será: "Pedrinho está acometido de um tumor maligno com crença total". Uma anotação $(0,3 ; 0,8)$, cai numa região cuja interpretação é "falso". Outras interpretações que a matriz possibilita são: falso tendendo ao inconsistente; quase inconsistente; inconsistente; verdadeiro tendente ao inconsistente; quase verdadeiro; verdadeiro; verdadeiro tendendo ao indeterminado; quase indeterminado; indeterminado; falso tendendo ao indeterminado; e quase falso.

Na lógica paraconsistente os graus de certeza (que é composto pelos graus de verdade e falsidade) e de contradição (que é composto pelos graus de inconsistência e de indeterminação), podem ser utilizados como sinais de informação. 0 output expressa uma decisão a ser seguida.

Maia et al. (2008) afirmam que a lógica Paraconsistente não é motivada somente por considerações filosóficas, mas também por suas aplicações e implicações. Uma das aplicações é a Automatização do Raciocínio (processamento de informações). Considere um computador que armazena uma grande quantidade de informações. Enquanto o computador armazena a informação, ele também é utilizado para operar e para inferir sobre ela. É muito comum os computadores conterem informações inconsistentes, por causa de erros humanos durante a digitação de dados, ou pela obtenção de dados de múltiplas fontes. Técnicas para remover informações inconsistentes têm sido investigadas, mas suas aplicações ainda são limitadas e em vários casos não garantem a produção de consistência.

Em Da Costa (1999) tem se que na lógica paraconsistente, as anotações são representativas de graus de crença e descrença atribuídos à proposição, dando-lhe conotações de valoração. 0 método consiste em estabelecer as proposições e parametrizá-las de forma a poder "isolar os fatores de maior influência nas decisões e, por meio de especialistas, obter anotações para esses fatores, atribuindolhes um grau de crença $(\mu 1)$ e um grau de descrença ( $\mu 2)$ ", é importante observar que esses valores são independentes e podem variam de 0 a 1 (CARVALHO, 2002). 
Para Carvalho; Brunstein e Abe (2003) as lógicas paraconsistentes anotadas são uma família de lógicas não-clássicas, inicialmente, empregadas em programação lógica. Posteriormente, várias aplicações foram estendidas por Blair, Subrahmanian, Kifer e outros. Devido às aplicações obtidas, tornou-se conveniente um estudo dos fundamentos da lógica subjacente às linguagens de programação investigadas. Verificou-se que se tratava de uma lógica paraconsistente e que, em alguns casos, também continha características da lógica paracompleta e não-alética.

Um tipo de lógica paraconsistente anotada é a bivalorada (LPA2v) que associa a cada proposição uma anotação $(\mu 1, \mu 2)$. De acordo com Carvalho (2002, p.58) a LPA2v, embora de criação muito recente, vem encontrando a aplicações em diversos campos de atividades.

\section{MÉTODOS E PROCEDIMENTOS}

De acordo com Da Costa et al. (1999, p.19), as lógicas anotadas constituem uma classe de lógicas paraconsistentes e acham-se relacionadas a certo reticulado completo denominado QUPC - Quadrado Unitário do Plano Cartesiano, como mostra a figura 1.

Figura 1: Reticulado denominado quadrado unitário do plano cartesiano (QUPC) para interpolação da resultante dos juízos expressos pelo par (grau de crença; grau de descrença).

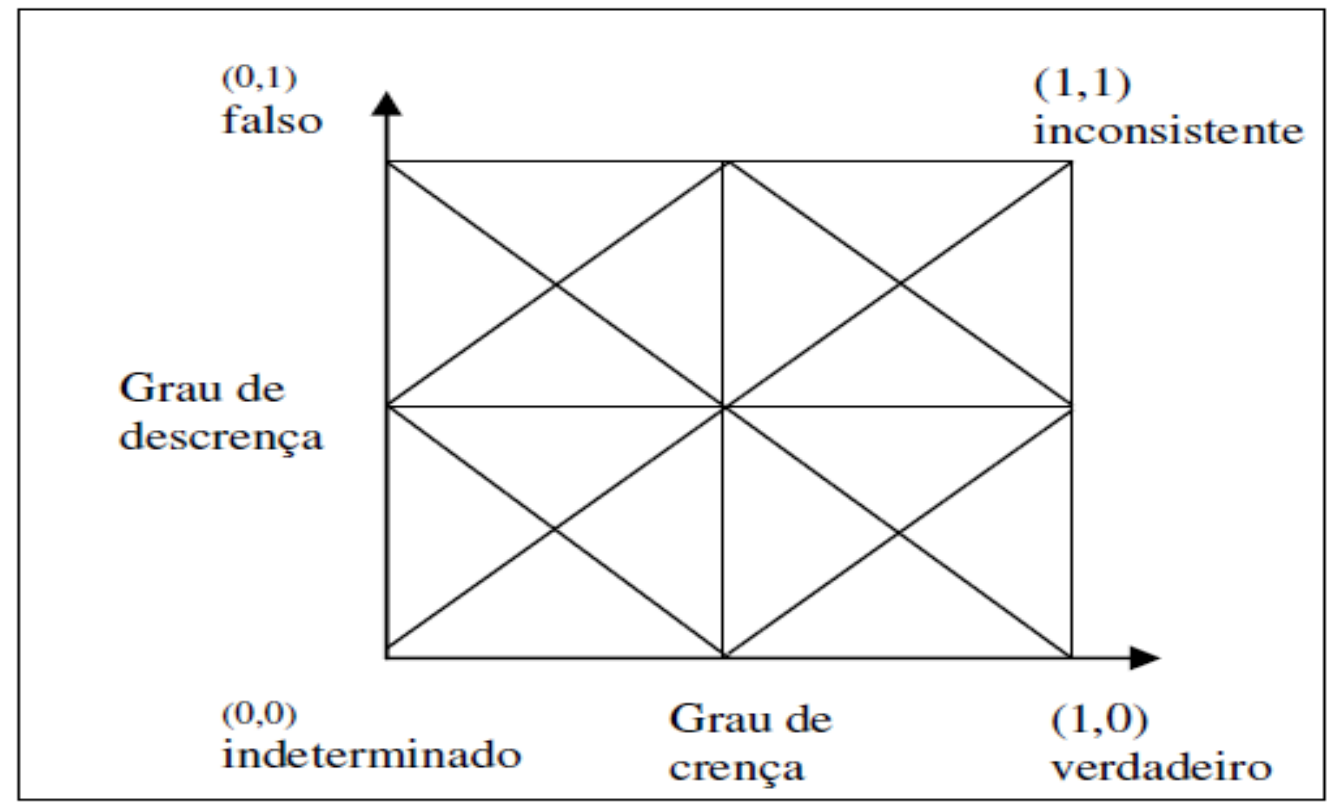

Fonte: Da Costa et. all (1999)

Para uma dada proposição de crença $\mu 1$ e descrença $\mu 2$, constitui-se o par $(\mu 1 ; \mu 2)$ que pertence ao produto cartesiano $[0,1 ; 0 ; 1]$ no QUPC. Os valores de crença $\mu 1$ e descrença $\mu 2$, podem ser quaisquer no intervalo fechado [0;1], destacando-se os seguintes pares $(\mu 1 ; \mu 2)$ :

- (0;0): falta total de crença e descrença (indeterminação);

- $(1 ; 1)$ : crença e descrença máximas (inconsistência);

- $(1 ; 0)$ : crença total e nenhuma descrença (verdade);

- $(0 ; 1)$ : nenhuma crença e descrença total (falso).

Cabe ressaltar que, partindo do grau de crença (GÇ) e do grau de descrença (GDÇ) é possível estabelecer o grau de contradição (GCT) e o grau de certeza (GC), como mostra a figura 2 . 0 grau de contradição GCT, segundo Da Costa et al. $(1999$, p.75) está no intervalo fechado [-1;+1] e é composto pelo grau de indeterminação Gid e pelo grau de inconsistência Git. 0 grau de certeza GC, está no intervalo fechado $[-1 ;+1]$ e é composto pelo grau de falsidade Gf e pelo grau de verdade Gv. 0 grau de 
contradição é dado por: GCT $=\mu 1+\mu 2-1$ e o grau de certeza é dado por: $\mathrm{GC}=\mu 1-\mu 2$.

Figura 2: Eixos do grau de contradição e do grau de certeza.

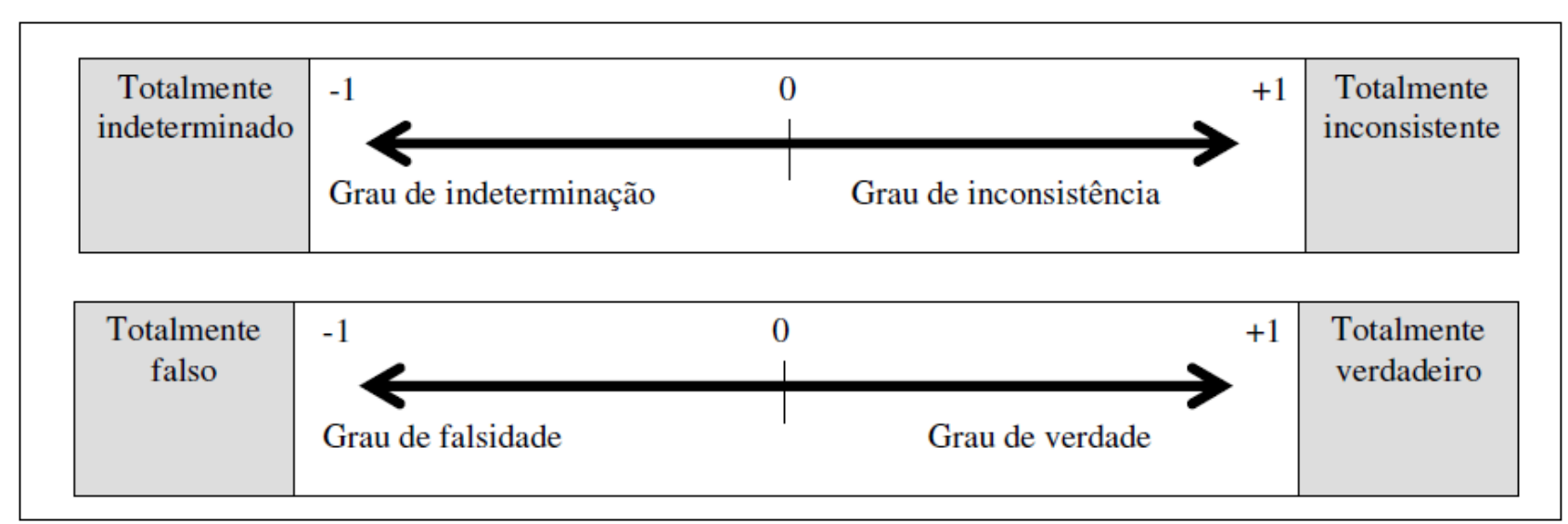

Fonte: Da Costa et. all (1999, p. 75)

A coleta de dados, ou seja, as anotações sobre os fatores a serem parametrizados pela LPA, se deu junto aos três sócios-gerentes da empresa, na medida em que conhecem profundamente o valor profissional de cada um dos seus funcionários. Portanto, estes, foram considerados especialistas e designados por Ei. Os especialistas Ei foram chamados a opinar sobre algumas características dos candidatos ao posto de gerente, atendendo a alguns pressupostos de Baush (1991, p.16), divididos em quatro grupos:

Grupo 1 - Empreendedorismo:

- capacidade de identificar prioridades;

- disposição para correr riscos e responsabilidade;

- habilidade para identificar oportunidades;

- capacidade de operacionalizar idéias;

\section{Grupo 2 - Liderança:}

- capacidade de delegar funções;

- capacidade de trabalho em equipe;

- capacidade de liderança;

Grupo 3 - Comunicação:

- facilidade de relacionamento interpessoal;

- capacidade de estabelecer e consolidar relações;

- capacidade de comunicação, redação e criatividade;

- capacidade de subordinar-se e obedecer à autoridade;

Grupo 4 - Métodos:

- domínio de métodos e técnicas de trabalho;

- capacidade de adaptar-se a normas e procedimentos. 
Utilização da lógica paraconsistente em processos de tomada

de decisão: um caso prático

Quadro 1: Respostas dos especialistas quanto a aceitação e rejeição das proposições sobre o funcionário Mário

\begin{tabular}{|c|c|c|c|c|c|c|}
\hline \multicolumn{7}{|c|}{ Avaliação de Funcionário para Promoção } \\
\hline Funcionário: Mário & Especi & alista 1 & Especi & alista 2 & Espec & alista 3 \\
\hline Assertiva & Aceit. & Rejeiç. & Aceit. & Rejeiç. & Aceit. & Rejeiç. \\
\hline \multicolumn{7}{|c|}{ Empreendedorismo } \\
\hline capacidade de identificar prioridades & 7 & 4 & 8 & 3 & 10 & 2 \\
\hline disposição para correr riscos e responsabilidade & 3 & 8 & 2 & 8 & 5 & 5 \\
\hline habilidade para identificar oportunidades & 8 & 4 & 7 & 3 & 6 & 1 \\
\hline capacidade de operacionalizar idéias & 7 & 4 & 5 & 4 & 8 & 5 \\
\hline \multicolumn{7}{|c|}{ Liderança } \\
\hline capacidade de delegar funções & 9 & 3 & 9 & 3 & 8 & 2 \\
\hline capacidade de trabalho em equipe & 5 & 2 & 7 & 4 & 7 & 3 \\
\hline capacidade de liderança & 10 & 2 & 9 & 1 & 9 & 2 \\
\hline \multicolumn{7}{|c|}{ Comunicação } \\
\hline facilidade de relacionamento interpessoal & 10 & 4 & 9 & 2 & 8 & 1 \\
\hline capacidade de estabelecer e consolidar relações & 10 & 5 & 8 & 2 & 8 & 1 \\
\hline capacidade de comunicação, redação e criatividade & 8 & 6 & 7 & 5 & 7 & 4 \\
\hline $\begin{array}{r}\text { capacidade de subordinar-se e obedecer à } \\
\text { autoridade }\end{array}$ & 9 & 5 & 8 & 3 & 9 & 2 \\
\hline \multicolumn{7}{|c|}{ Métodos } \\
\hline domínio de métodos e técnicas de trabalho & 10 & 3 & 10 & 2 & 10 & 2 \\
\hline capacidade de adaptar-se a normas e procedimentos & 8 & 3 & 9 & 3 & 8 & 1 \\
\hline $\begin{array}{l}\text { A valiação global: nota de zero a dez indicando a cap } \\
\text { do funcionário para assumir a gerência }\end{array}$ & acidade & 9 & & 10 & & 9 \\
\hline
\end{tabular}

Fonte: Autores

Observar que os pressupostos teóricos que presidem à escolha dos candidatos foram adotados pela empresa, centram-se em Baush (1991, p.16) e não são relevantes para a presente pesquisa porquanto a técnica de tomada de decisão que aqui se discute é indiferente a tais pressupostos. Com base nestes pressupostos elaborou-se um questionário estruturado que foi apresentado aos especialistas para que eles emitissem sua opinião sobre os funcionários. Foi solicitada também uma avaliação global: nota de zero a dez indicando a capacidade do funcionário para assumir a gerência.

O quadro 1 mostra não só o questionário estruturado aplicado, mas, também, a tabulação das respostas oriundas dos três especialistas com relação a um dado funcionário. Respostas semelhantes foram coletadas sobre os demais candidatos.

Os especialistas receberam o questionário e a seguinte orientação: "Para cada assertiva solicitamos que atribua uma nota de zero a 10 pontos em cada coluna (crença e 99 descrença), expressando sua opinião, respectivamente positiva e negativa, quanto ao quesito".

Por exemplo, para avaliar as assertivas "capacidade de identificar prioridades" e "disposição para correr riscos e responsabilidade", o Especialista pode responder com uma avaliação contendo números de 0 a 10 como ilustra a Tabela 1. 
Tabela 1: - Exemplo de respostas válidas.

\begin{tabular}{|c|c|c|c|c|c|}
\hline \multicolumn{6}{|l|}{ Funcionário: Mário } \\
\hline Assertiva & Aceit. & Rejeiç. & Fator AF & $\begin{array}{l}\text { Grau de } \\
\text { Crença }\end{array}$ & $\begin{array}{l}\text { Grau de } \\
\text { descrença }\end{array}$ \\
\hline \multicolumn{6}{|l|}{ Empreendedorismo } \\
\hline capacidade de identificar prioridades & 7 & 4 & 0,913 & 0,58 & 0,33 \\
\hline disposição para correr riscos e responsabilidade & 3 & 8 & 0,913 & 0,25 & 0,66 \\
\hline habilidade para identificar oportunidades & 8 & 4 & 0,846 & 0,56 & 0,28 \\
\hline capacidade de operacionalizar idéias & 7 & 4 & 0,913 & 0,58 & 0,33 \\
\hline & & & & 0,49 & 0,40 \\
\hline
\end{tabular}

Fonte: Autores

\section{DESCRIÇÃO E ANÁLISE DE DADOS}

Considerando as respostas obtidas em cada questionário, construiu-se o grau de crença (GC) que exprime o nível de aceitação de uma dada assertiva pelo especialista em relação a cada um dos funcionários em análise (Abel, Mário, Júlio, José, Rui). Os graus de crença e de descrença foram calculados respectivamente de acordo com as seguintes equações:

$$
G_{\zeta}=\left[1-\left(\frac{1}{\frac{A}{R}+1}\right)\right] * A F \quad G_{D \zeta}=\left[1-\left(\frac{1}{\frac{R}{A}+1}\right)\right] * A F
$$

onde:

GÇ: Grau de crença

GDÇ:Grau de descrença

A: Aceitação- grau de aceitação da proposição num intervalo [0, 10]

R: Rejeição- grau de rejeição da proposição num intervalo $[0,10]$

AF: "asymetry factor"- fator de assimetria

Esta fórmula foi concebida por Wilder Jr (1981) e tem o nome de Índice de Força Relativa, sendo também conhecido como Indicador de Opinião Contrária. Para evitar erro de divisão por valor nulo, quando for o caso se acrescenta a $\mathrm{A}$ ou a B o valor 0,00001. Por exemplo, os graus de crença e descrença do Especilista 1, em relação ao candidato Mário, no que se refere à proposição "capacidade de identificar prioridades", para os valores 7 e 4, respectivamente de aceitação e de rejeição, são:

$$
G_{C}=\left[1-\left(\frac{1}{\frac{7}{4}+1}\right)\right] * 0,913=0,581
$$

$$
G_{D C}=\left[1-\left(\frac{1}{\frac{4}{7}+1}\right)\right] * 0,913=0,331
$$

Foi considerado um fator de assimetria (asymetry factor) que exprime a relação entre 10 e a soma dos pontos atribuídos para avaliar a assertiva. 0 fator de assimetria nada mais é do que um lognormalizador para uma escala 0-10: multiplicando-se o fator de assimetria por (Crença+Descrença) obtém-se o valor 10. Se o respondente atribui pesos cuja soma corresponde a 10, AF tem valor unitário; diferentemente disso AF tem o valor dado pela fórmula a seguir. Por exemplo, o cálculo do 
fator de assimetria para o presente caso é:

$$
A F=\frac{e^{\left(\frac{10}{A+R}\right)}}{e}=\frac{e^{\left(\frac{10}{7+4}\right)}}{e}=\frac{e^{(0,9091)}}{e}=0,913
$$

onde:

AF: "asymetry factor"- fator de assimetria

A: Aceitação- grau de aceitação da proposição num intervalo $[0,10]$

R: Rejeição- grau de rejeição da proposição num intervalo $[0,10]$

Um AF igual a 1 significa que a soma de A e R é igual a 10. Após o cálculo do grau de crença (GÇ) e descrença (GDÇ) para cada assertiva e para cada Especialista, foi feita a análise conforme o modelo da Lógica paraconsistente Anotada de Anotação com Dois Valores (LPA2V).

Os graus de crença e descrença de cada proposição constituíram-se pelo valor médio. Estes cálculos foram feitos para os três Especialistas. No que diz respeito ao funcionário Mário, os resultados obtidos são exibidos no Quadro 2. 
Cida Sanches, Manuel Meireles, Marcio Luiz Marietto, Orlando Roque da Silva e José Osvaldo de Sordi

Quadro 2: Cálculos dos graus de crença e de descrença dos três especialistas em relação a um dos funcionários

\begin{tabular}{|c|c|c|c|c|c|c|}
\hline \multicolumn{7}{|c|}{ Avaliação de Funcionário para Promoção } \\
\hline \multirow{2}{*}{$\begin{array}{l}\text { Funcionário: Mário } \\
\text { Assertiva }\end{array}$} & \multicolumn{2}{|c|}{ Especialista 1} & \multicolumn{2}{|c|}{ Especialista 2} & \multicolumn{2}{|c|}{ Especialista 3} \\
\hline & $\begin{array}{l}\text { Grau de } \\
\text { Crença }\end{array}$ & $\begin{array}{c}\text { Grau de } \\
\text { Descrença }\end{array}$ & $\begin{array}{l}\text { Grau de } \\
\text { Crença }\end{array}$ & $\begin{array}{c}\text { Grau de } \\
\text { Descrença }\end{array}$ & $\begin{array}{l}\text { Grau de } \\
\text { Crença }\end{array}$ & $\begin{array}{l}\text { Grau de } \\
\text { Descrença }\end{array}$ \\
\hline \multicolumn{7}{|c|}{ Empreendedorismo } \\
\hline capacidade de identificar prioridades & 0,58 & 0,33 & 0,66 & 0,25 & 0,70 & 0,14 \\
\hline $\begin{array}{r}\text { disposição para correr riscos e } \\
\text { responsabilidade }\end{array}$ & 0,25 & 0,66 & 0,20 & 0,80 & 0,50 & 0,50 \\
\hline habilidade para identificar oportunidades & 0,56 & 0,28 & 0,70 & 0,30 & 1,31 & 0,22 \\
\hline \multirow[t]{2}{*}{ capacidade de operacionalizar idéias } & 0,58 & 0,33 & 0,62 & 0,50 & 0,49 & 0,31 \\
\hline & 0,49 & 0,40 & 0,55 & 0,46 & 0,75 & 0,29 \\
\hline \multicolumn{7}{|c|}{ Liderança } \\
\hline capacidade de delegar funções & 0,63 & 0,21 & 0,63 & 0,21 & 0,80 & 0,20 \\
\hline capacidade de trabalho em equipe & 1,10 & 0,44 & 0,58 & 0,33 & 0,70 & 0,30 \\
\hline capacidade de liderança & 0,70 & 0,14 & 0,90 & 0,10 & 0,75 & 0,17 \\
\hline & 0,81 & 0,26 & 0,70 & 0,21 & 0,75 & 0,22 \\
\hline \multicolumn{7}{|c|}{ Comunicação } \\
\hline facilidade de relacionamento interpessoal & 0,54 & 0,21 & 0,75 & 0,17 & 0,99 & 0,12 \\
\hline $\begin{array}{r}\text { capacidade de estabelecer e consolidar } \\
\text { relações }\end{array}$ & 0,48 & 0,24 & 0,80 & 0,20 & 0,99 & 0,12 \\
\hline $\begin{array}{r}\text { capacidade de comunicação, redação e } \\
\text { criatividade }\end{array}$ & 0,43 & 0,32 & 0,49 & 0,35 & 0,58 & 0,33 \\
\hline \multirow[t]{2}{*}{$\begin{array}{r}\begin{array}{r}\text { capacidade de subordinar-se e obedecer à } \\
\text { autoridade }\end{array} \\
\end{array}$} & 0,48 & 0,27 & 0,66 & 0,25 & 0,75 & 0,17 \\
\hline & 0,48 & 0,26 & 0,68 & 0,24 & 0,83 & 0,19 \\
\hline \multicolumn{7}{|c|}{ Métodos } \\
\hline domínio de métodos e técnicas de trabalho & 0,61 & \begin{tabular}{|l|}
0,18 \\
\end{tabular} & 0,70 & 0,14 & 0,70 & 0,14 \\
\hline \multirow[t]{2}{*}{$\begin{array}{r}\text { capacidade de adaptar-se a normas e } \\
\text { procedimentos }\end{array}$} & 0,66 & 0,25 & 0,63 & 0,21 & 0,99 & 0,12 \\
\hline & 0,64 & 0,22 & 0,67 & 0,18 & 0,85 & 0,13 \\
\hline \multicolumn{2}{|c|}{$\begin{array}{l}\text { A valiação global: nota de zero a dez indicando a } \\
\text { capacidade do funcionário para assumir a gerência }\end{array}$} & 9 & & 10 & & 9 \\
\hline
\end{tabular}

Fonte: Autores

As figuras 3 e 4 referem-se à análise, pela lógica paraconsistente anotada (LPA), das assertivas referentes a empreendedorismo pertinentes ao funcionário Mário. A figura 5 exibe a interpretação gráfica dos resultados da análise pela Lógica Paraconsistente de todas as proposições: empreendedorismo, liderança, comunicação e métodos.

O output de um conectivo OR é o maior valor das entradas; o output de um conectivo AND é o menor valor das entradas. 
Figura 3: Análise pela Lógica Paraconsistente das proposições referentes a empreendedorismo [Mário]

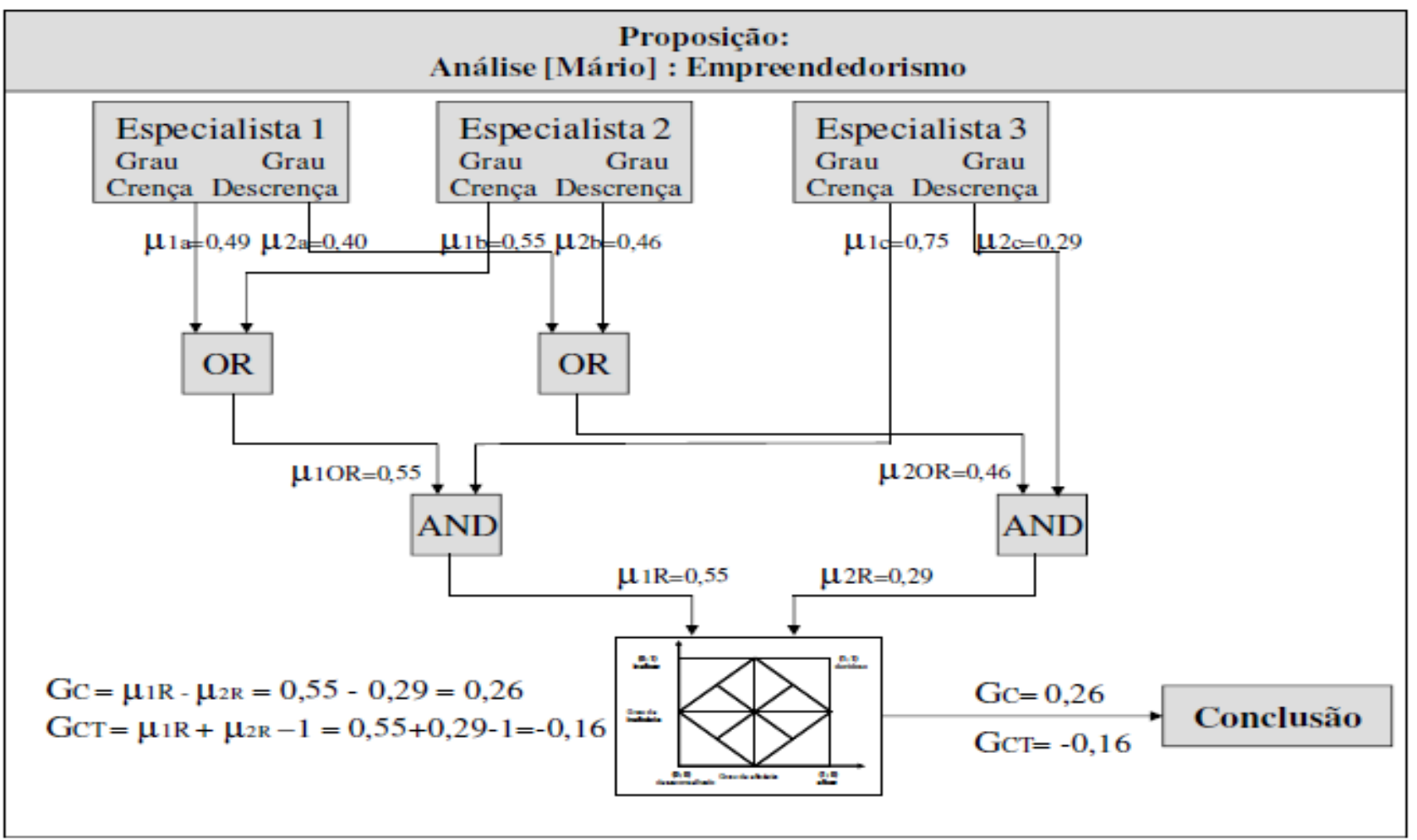

Fonte: Autores

Figura 4: Interpretação gráfica no QUPC do resultado da análise pela Lógica Paraconsistente das proposições referentes a empreendedorismo [Mário].

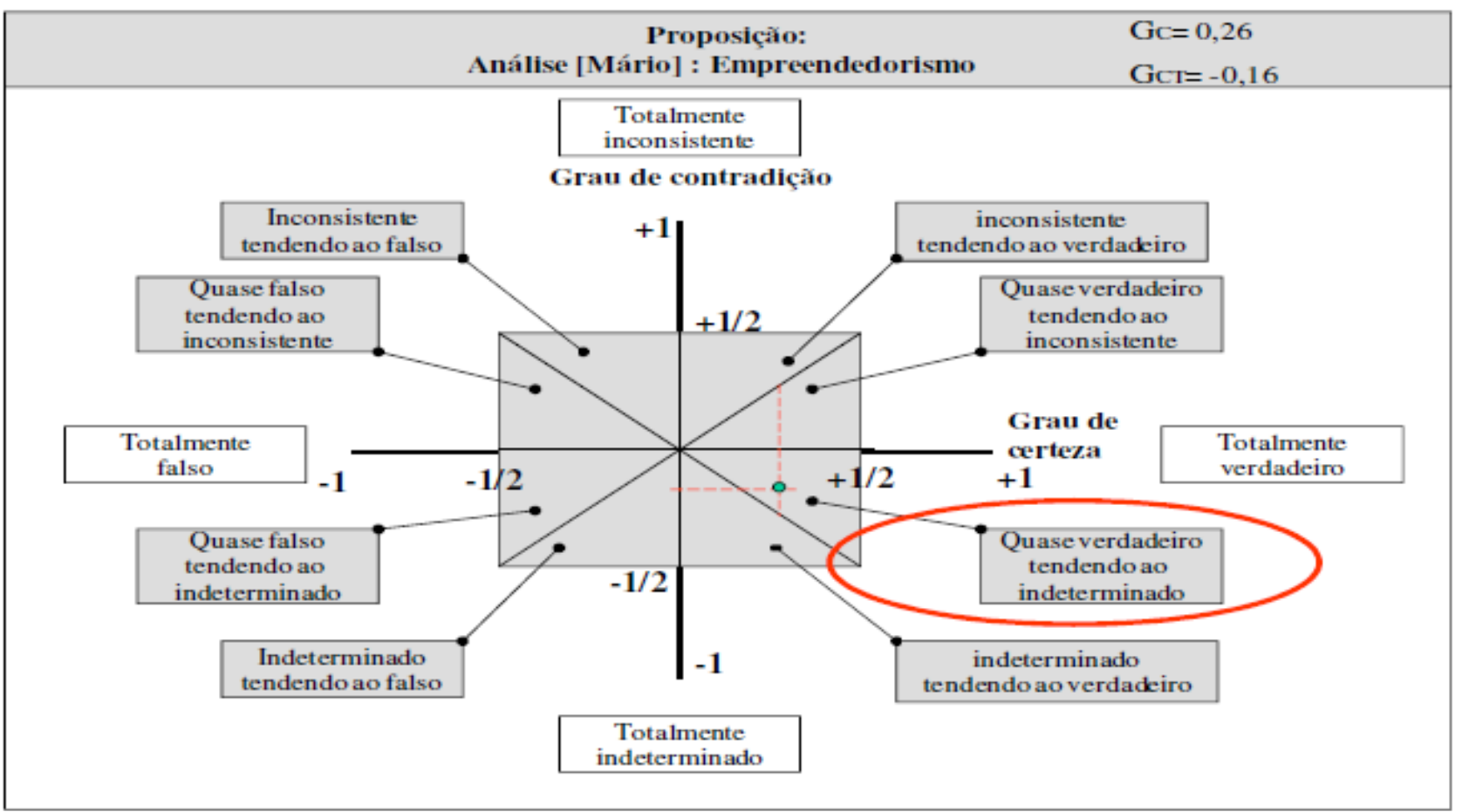

Fonte: Autores

0 modelo de rede OR e AND para três especialistas (figura 3) foi obtido em DA COSTA et al. (1999, p.131). As informações vindas dos três especialistas, que podem ser conflitantes e imprecisas, são 
sintetizadas num resultado denominado "conclusão" que expressa o grau de crença (GC) e o grau de contradição (GCT). 0 grau de crença expressa a evidência favorável à proposição, e o grau de descrença a evidência contrária à proposição, de acordo com DA COSTA et al. (1999, p.43).

Os valores de grau de crença e de descrença são completamente independentes e é possível qualquer variação dos valores no intervalo fechado entre 0 e 1 . Tais valores são posicionados no quadrado unitário do plano cartesiano (QUPC) para uma interpretação gráfica. O modelo do QUPC foi extraído de DA COSTA (1999, p.78). De acordo com estes autores (p.95), a representação da LPA2v através do reticulado com valores dos graus de certeza e de incerteza e sendo analisada no QUPC permite que os valores limites de controle sejam variados externamente. No QUPC cada região equivale a um estado lógico resultante (ver, por exemplo, figura 5).

Figura 5: Interpretação gráfica no QUPC do resultado da análise pela Lógica Paraconsistente das proposições referentes à liderança [Mário].

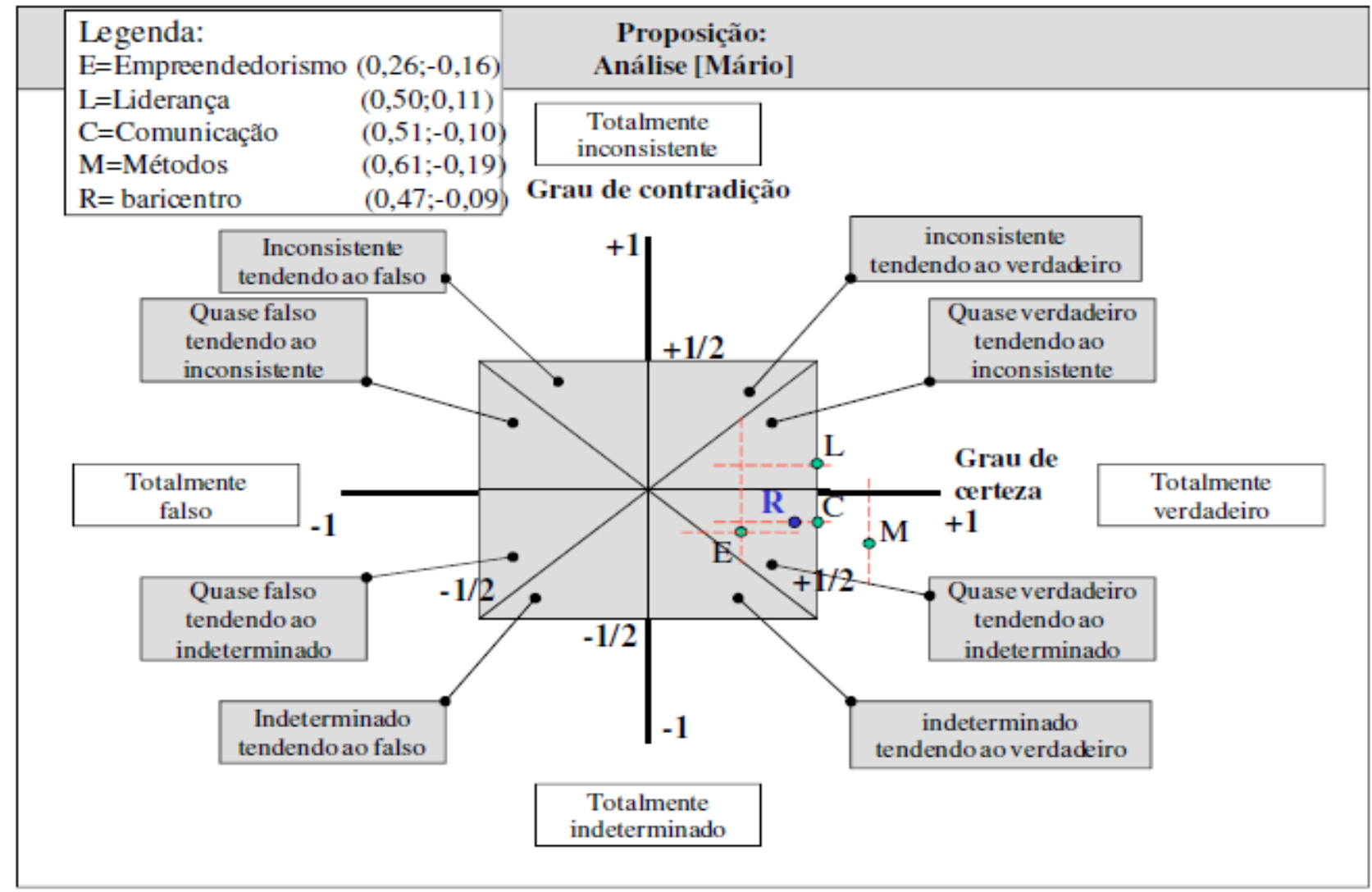

Fonte: Autores

Observar que para os quatro grupos de proposições (empreendedorismo, liderança, comunicação e métodos), Mário atingiu a região "quase verdadeiro". Quando há vários fatores, é possível representar todos os pontos por um único, chamado baricentro (R). De acordo com Carvalho (2002, p.83) o baricentro R é o centro geométrico dos pontos que representam os fatores de influência no QUPC e traduz de certa forma, a influência resultante de todos os fatores considerados na análise em curso. 0 baricentro $\mathrm{R}$ é obtido pelas médias aritméticas dos graus de crença e de descrença no caso de fatores com o mesmo peso. A figura 5 mostra o baricentro dos fatores referentes à análise de Mário; a figura 6 mostra os baricentros de todos os funcionários em análise (Abel, Mário, Júlio, José, Rui). 0 funcionário Mário é o que apresenta o baricentro com maior grau de certeza e foi o selecionado. 
Figura 6: Interpretação gráfica no QUPC dos resultados da análise pela Lógica Paraconsistente: baricentros.

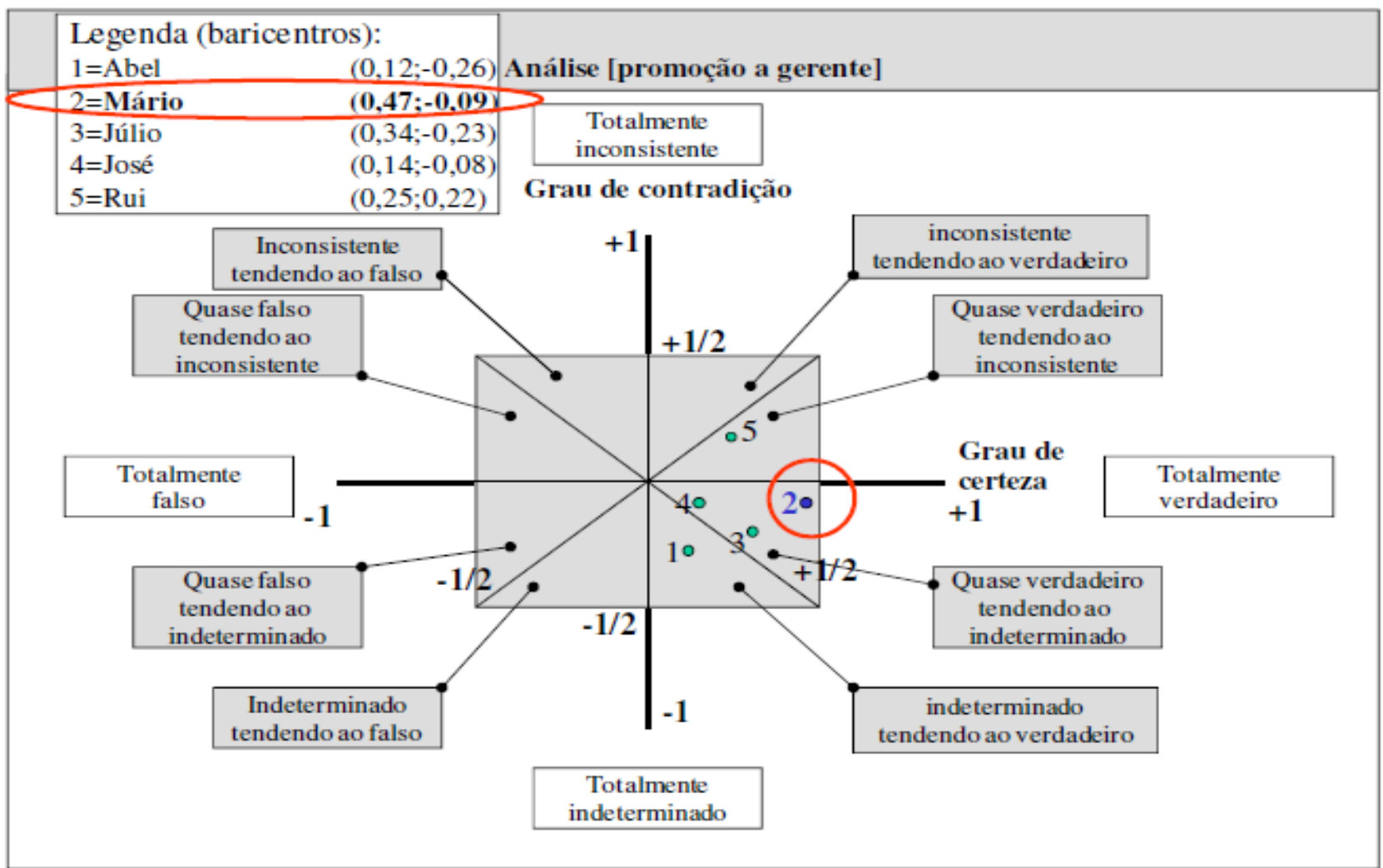

Fonte: Autores

\section{CONSIDERAÇÕES FINAIS}

Este trabalho ocupou-se da aplicação da lógica paraconsistente anotada para tomada de decisão no âmbito da gestão de recursos humanos. Os resultados foram coerentes com o que se esperava: o funcionário Mário foi promovido a gerente e era consenso dos especialistas que o menos habilitado era Abel. Pode-se dizer, portanto, que o método apresenta um alto grau de fidedignidade. A interpretação final se baseia na posição dos baricentros no quadrado unitário do plano cartesiano (QUPC) indicando, ainda, o grau de contradição e o grau de inconsistência ou de indeterminação dos dados utilizados.

Com efeito, este tipo de análise indica se há contradição entre os dados utilizados e se tal contradição é acentuada ou não, pelo posicionamento do baricentro $\mathrm{R}$ em relação à linha vertical. Indica, também, se a contradição apresentada é uma inconsistência ou uma indeterminação (falta de informações). No presente caso, o baricentro 5 tende à inconsistência enquanto o baricentro 1 tende à indeterminação. Carvalho (2002, p.104) argumenta que além de aceitar dados contraditórios o método ainda dá indicações sobre os graus de contradição desses dados, o que só é possível, no entender do autor, pelo fato de o método ser a Lógica Paraconsistente Anotada bivalorada (LPA2v), lógica que aceita contradições sem se tornar trivial.

A utilização da Lógica Paraconsistente Anotada bivalorada (LPA2v) está se estendendo na tomada de decisão em Administração como mostram Abe (2003), Carvalho; Brunstein e Abe (2003), Chagas e Freitas (2001), Carvalho (2002). Pode-se concluir, seguindo as mesmas considerações de Domingues et alli (2004) que este método usando a Lógica Proposicional Paraconsistente Anotada, oferece solução para processos de tomada de decisão no campo da administração. 0 caso apresentado associa-se à solução de problemas ligados à gestão de recursos humanos. Como exposto, a lógica paraconsistente fornece novas técnicas de análise mais apropriadas, principalmente na presença de dados incertos e contraditórios, permitindo manipular tais dados de modo não trivial. Os autores 
acreditam que a técnica apresentada aqui abre novas formas de tratamento e desenvolvimento ulteriores.

\section{REFERÊNCIAS}

ABE, J.M., Fundamentos da lógica anotada, 1992, 139 f.. Tese (Doutorado em Filosofia). Departamento de Filosofia da Faculdade de Filosofia, Ciências e Letras da Universidade de São Paulo, São Paulo, 1992.

BAUSH, Thomas A. O significado de mudanças curriculares das faculdades de Administração da América Latina. In: Encontro Nacional dos Cursos de Graduação em Administração, 2., 1991. Anais... São Paulo, USP, 1991.

BOURDIEU, P. À propos de la famille comme catégoei réalisée. Actes De La Recherche En Sciences Sociales, Paris, v. 100, p. 32-36, 1993.

CARVALHO, F.R. Lógica paraconsistente aplicada em tomadas de decisão. São Paulo: Aleph, 2002.

CARVALHO, F.R.; BRUNSTEIN, I; ABE, J.M. Um Estudo de Tomada de Decisão Baseado em Lógica Paraconsistente Anotada: Avaliação do Projeto de uma Fábrica. Revista Pesquisa e Desenvolvimento Engenharia de Produção, Itajubá, n.1, p. 47-62, dez. 2003

CERQUIRA, L.A.; OLIVA,A. Introdução à Lógica. Rio de Janeiro: Zahar, 1979.

CHAGAS, J.O.; FREITAS, H.M.R. A tomada de decisão segundo o comportamento

empreendedor: uma survey na Região das Missões. In: Encontro da Associação Nacional de PósGraduação e Pesquisa em Administração, 15., 2001. Anais... Rio de Janeiro, EnANPAD, 2001.

COPI, I. M. Introdução à lógica. São Paulo: Mestre Jou, 1981.

DA COSTA, N.C. A Lógica Paraconsistente Aplicada. São Paulo, Atlas, 1999.

DA COSTA, N.C.; ABE, J.M.; MUROLO, A.C.; SILVA FILHO, J.I.; LEITE, C.F.S. Lógica paraconsistente anotada. São Paulo: Atlas, 1999.

DOMINGUES, M.A.; BRUNSTEIN,I.;ABE,J.M. Proposta de uso da Lógica Paraconsistente Anotada na análise do poder de competição: o estudo do fator "Dificuldades à entrada dos concorrentes". In: XXIV Encontro Nacional de Engenharia de Produção, 2004... Anais...Florianópolis, ENEGEP, 2004.

FLETCHER, D. Family and enterprise. In: CARTER, S.; JONES-EVANS, D. (Org.) Enterprise and small business: principles, practice and policy. Essex: Pearson Education Limited, 2000.

FLETCHER, D. Swimming around in their own ponds: the weakness of strong ties in developing innovative practices. International Journal of Innovation Management, v. 2, n. 2, p. 137-159, 1998.

FREITAS, H.; MACADAR, M.A.; MOSCAROLA, J. Informação e Decisão: sistemas de apoio e seu impacto. Porto Alegre: Ortiz, 1997.

HASEGAWA. F. M. Uma abordagem baseada em lógica Paraconsistente para avaliação de ofertas em negociações entre organizações artificiais. Curitiba: Universidade Católica do Paraná, 2004. (Dissertação de Mestrado)

ITO, O.T.; ALBUQUERQUE, A.R.P.L.; CAMPOS, I.P.A. Aplicação da lógica paraconsistente anotada no estudo de questionário com informações redundantes. In: Simpoi, 12, 2009.. Anais... São Paulo, SIMPOI, 2009.

JONES, M. H. Tomada de decisão pelo executivo. São Paulo: Atlas. 1973.

KATZ, Robert. As habilidades de um administrador eficiente. In: Harvard Business Review. São Paulo: Nova Cultura Ltda., 1986, p. 57-92

LEVIN, I. Family as mapped realities. Journal of Family Issues, v. 14, n. 1, p. 82-91, 1993. 
MAIA, D.A.O.F.; NOBRE, E.F.; SANTOS, M.V.S.; FERREIRA, S.N.M. Lógica Paraconsistente. Disponível em: <br.geocities.com/nao_classica/lp.doc>. Acesso em: 17 jan. 2008.

MINTZBERG, H. As atribuições do administrador, ficção e realidade. Diálogo, v. 10, n. 1, 1977

OLIVEIRA, K.R.; ABE, J.M.. Utilizando a lógica não-clássica para validar processos de negócios através da elicitação de requisitos. In: Encontro Nacional de Engenharia de Produção, 22., 2002.. Anais... Curitiba, ENEGEP, 2002.

PEREIRA, M.J.L.B. Faces da decisão: as mudanças de paradigmas e o poder da decisão. São Paulo. Makron Books. 1997.

RAM, M. Managing to survive: working lives in small firms. Oxford: Blackwell, 1994.

RAM, M.; HOLLIDAY, R. Relative merits: family culture and kinship in small firms. Sociology, v. 27, n. 4, p. 629-648, 1993.

SALMON, W. C. Lógica. Rio de Janeiro: Zahar, 1984.

SIMON, H.A. Comportamento Administrativo. Rio de Janeiro: FGV, 1965.

TEIXEIRA, H. J. ; PELLEGATTI, M. . Informações, decisões e atuação dos executivos. Revista de Administração (USP), São Paulo, v. 21, p. 54-57, 1986.

WILDER JR, W. New concepts in technical trading systems. New York: Trend Research, 1981. 